\title{
A study of mitochondria in spinal ganglion neurons during life: Quantitative changes from youth to extremely advanced age
}

\author{
C. Martinelli, P. Sartori, M. Ledda, E. Pannese* \\ Institute of Histology, Embryology and Neurocytology, University of Milan, Via Mangiagalli 14, I-20133 Milan, Italy
}

Received 30 September 2005; received in revised form 14 December 2005; accepted 19 December 2005

\begin{abstract}
In view of the central role that mitochondria are thought to play in the ageing process, we investigated changes in mitochondria of spinal ganglion neurons in rabbits aged 1, 3.6, 6.7, and 8.8 years (the latter extremely old). Mitochondrial size increased significantly with age, while mitochondrial structure did not change. The total volume of mitochondria within the perikaryon did not change significantly during life. This indicates that in these neurons mitochondrial degradation was completely compensated by the production of new mitochondria even in the extremely advanced age. We also found that the mean volume of neuronal perikaryon increased markedly with age, so that the mean percentage of perikaryal volume occupied by mitochondria decreased significantly with a difference of about $33 \%$ between the youngest and the oldest animals. This decrease is only in very small part due to lipofuscin accumulation, so that the ratio of the total volume of mitochondria to the volume of functionally active cytoplasm decreased with age. The mitochondria of the neurons studied seem therefore unable to adapt their total volume to the volume of functionally active cytoplasm, that increases with age. This result is consistent with the observation that the neurons of old animals have a reduced ability to respond to high energy demands.
\end{abstract}

(c) 2006 Elsevier Ltd. All rights reserved.

Keywords: Dorsal root ganglia; Sensory neurons; Ageing; Oryctolagus cuniculus

\section{Introduction}

We have long been concerned with the structural changes that occur with age in the neurons and satellite glial cells of sensory ganglia. Numerous studies have revealed that mitochondrial function deteriorates during normal ageing and suggest that this process plays a central role in ageing (for reviews, see Miquel et al., 1980; Wallace, 1992; Kadenbach et al., 1995; Ozawa, 1995; Cortopassi and Wong, 1999; Walter et al., 1999). We have therefore resumed our studies on the age-related changes of mitochondria in the neurons of these ganglia. We have now extended our investigation to more specimens of the previously considered age groups (Ledda et al., 2001) and have also examined animals of extremely advanced age.

\footnotetext{
* Corresponding author. Tel.: +39 0250314660; fax: +39 0250314670 .

E-mail address: ennio.pannese@ unimi.it (E. Pannese).
}

\section{Materials and methods}

The present study was carried out on rabbits (Oryctolagus cuniculus) of both sexes. Rabbits aged 1 year (three animals, 3.4-3.5 kg body weight), 3.6 years (three animals, $3.6-3.8 \mathrm{~kg}$ body weight), 6.7 years (three animals, $4.0-4.2 \mathrm{~kg}$ body weight), and 8.8 years (three animals, $4.2-4.5 \mathrm{~kg}$ body weight) were used. The rabbits were cared for according to the European Community Council Directive (86/609/EEC) on the use of laboratory animals. The dates of birth of all animals were documented; all had been raised by a specialist rabbit breeder with particular attention to hygiene and regular veterinary inspections and had been fed an unrestricted diet. Because the mean life span of the normal healthy Oryctolagus is approximately 5.6 years (Harkness and Wagner, 1983) and the maximal life span is approximately 8 years (Weisbroth et al., 1974), the 1-year-old rabbits we studied were young, the 3.6-year-old rabbits were adult, the 6.7-year-old rabbits were old, and the 8.8-year-old animals were very old. 
The animals were perfused transcardially with a solution containing $2 \%$ formaldehyde and $2 \%$ glutaraldehyde in $0.1 \mathrm{M}$ sodium cacodylate buffer $(\mathrm{pH}$ 7.3) under deep anaesthesia with nembutal i.p. $(80 \mathrm{mg} / \mathrm{kg})$. After fixation for about $3 \mathrm{~h}$, the thoracic spinal ganglia were removed, washed in cacodylate buffer $(0.2 \mathrm{M}, \mathrm{pH} 7.3)$ for $2 \mathrm{~h}$ and then postfixed on ice for $1.5 \mathrm{~h}$ in $2 \% \mathrm{OsO}_{4}$, buffered with $0.1 \mathrm{M}$ sodium cacodylate. The specimens were washed in distilled water, stained with $2 \%$ aqueous uranyl acetate, dehydrated in alcohol and embedded in Epon-Araldite resin. Several semithin sections were prepared from each ganglion and stained with $0.5 \%$ toluidine blue in $1 \%$ sodium borate. They were then examined in the light microscope to check the quality of fixation. Only the best-preserved ganglia were used and none of the nerve cell bodies in these ganglia showed signs of swelling or shrinkage. Overall, 96 ganglia (8 for each animal) were used for this study.
Isotropic uniform random (IUR) sections were obtained following the orientator procedure (Mattfeldt et al., 1990). For each ganglion, a single IUR thin section (about $0.25 \mathrm{~mm} \times 0.20 \mathrm{~mm}$ ) was photographed under the electron microscope. Each section was photographed in its entirety at a magnification of $2500 \times$ and the negatives printed to a final magnification of $10,000 \times$. A montage of $60-70$ prints was necessary to reconstruct each section. A transparent sheet containing a series of points spaced at $1 \mathrm{~mm}$ intervals was randomly positioned over the photomontage. Next a sheet of cardboard containing uniform-sized $(10 \mathrm{~cm} \times 5 \mathrm{~cm})$, systematically arranged windows was placed over the transparent sheet and photomontage. For each section, all the points falling on the neuronal perikaryon $\left(P_{\mathrm{n}}\right)$ within each window were counted, as were all the points lying on the mitochondria $\left(P_{\mathrm{nm}}\right)$. The percentage of perikaryal volume (see below) occupied by mitochondria $\left(V_{\mathrm{vnm}}\right)$ was calculated from the

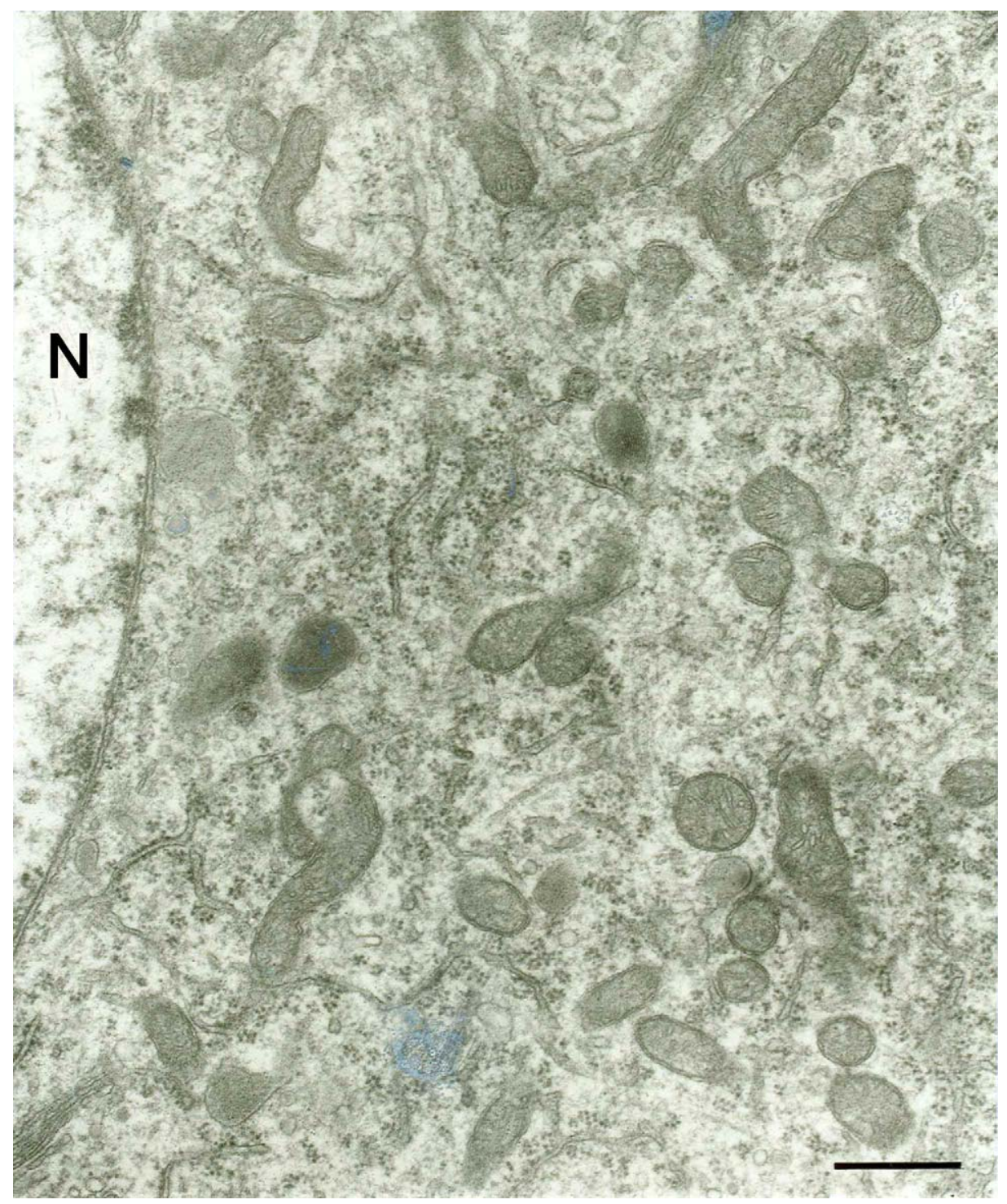

Fig. 1. Electron micrograph showing a portion of the nerve cell body of a spinal ganglion neuron. N, nucleus. Young rabbit (1 year). Bar, $0.5 \mu \mathrm{m}$. 
following formula: $V_{\mathrm{vnm}}=P_{\mathrm{nm}} \times 100 / P_{\mathrm{n}}$. The mean value of $V_{\mathrm{vnm}}( \pm$ S.E.) was calculated for each rabbit.

To obtain information on the size of the mitochondria, the number of test points lying on each mitochondrion within each window was determined. The mean number of points ( \pm S.E.) lying on a mitochondrion was then calculated for each animal. This number gives an indication of the size of the mitochondria under study.

Subsequently, numerous thin sections were cut from the part of each ganglion left after the preparation of the IUR thin section. These sections were used to determine the volume of neuronal perikarya. To this end the circle-fitting method was employed (see Pannese et al., 1972 for details). Two hundred and eighty nerve cell bodies in young animals, 275 in adult animals, 281 in old animals, and 266 in very old rabbits were used. The mean volume of the perikaryon was then calculated for each rabbit.
From the mean volume of the perikaryon and the percentage of that volume occupied by mitochondria, the total volume of mitochondria within the perikaryon was calculated for each rabbit.

The values obtained for the three rabbits in each age group were compared by one-way ANOVA to establish whether they differed significantly. Subsequently, the mean values obtained for each age group were compared. The latter statistical comparison employed the post hoc Tukey test for multiple comparisons. Values were expressed as the mean \pm S.E. Changes were identified as significant if $P$ was less than 0.05. All data analyses were carried out using SPSS 11.0 software.

Finally, the mean percentage of the perikaryal volume occupied by mitochondria and the mean size of mitochondria in large light and in small dark neurons were compared by one-way ANOVA.

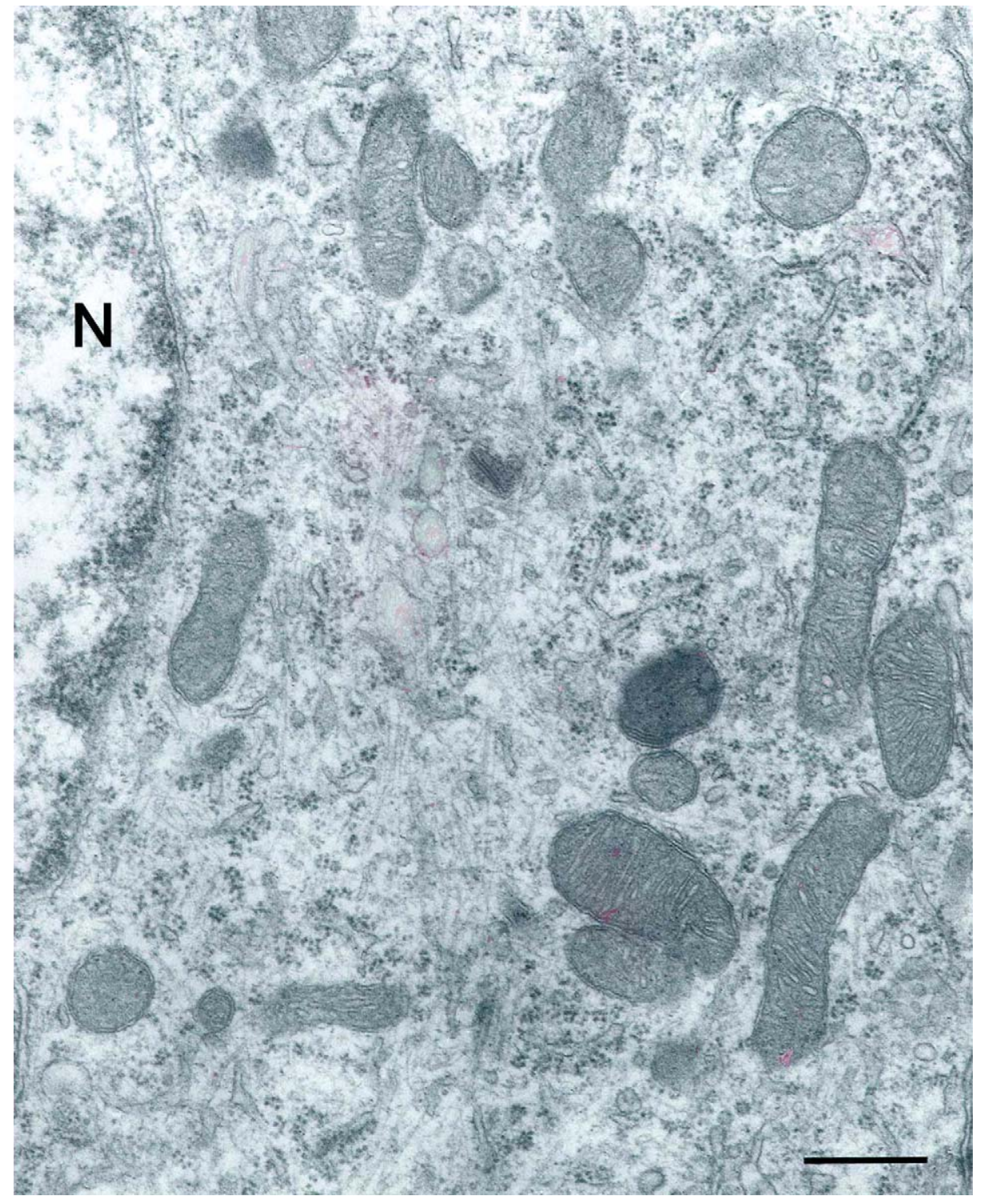

Fig. 2. Electron micrograph showing a portion of the nerve cell body of a spinal ganglion neuron. N, nucleus. Very old rabbit ( 8.8 years). Bar, $0.5 \mu \mathrm{m}$. 


\section{Results}

The sensory neuron mitochondria showed the distinctive structural features well known from the literature (e.g. see Pannese, 1994). Their structure (Figs. 1 and 2) did not differ in the four age groups. In particular, swollen or degenerating mitochondria were absent in all preparations.

Our main findings are as follows: (1) the total volume of mitochondria within the perikaryon did not differ significantly between age groups (Fig. 3), while the mean volume of neuronal perikaryon increased markedly with age; (2) the mean percentage of perikaryal volume occupied by mitochondria decreased significantly with age (Fig. 4) with a difference of about $33 \%$ between the youngest and the oldest animals; (3) the mean number of points falling on a mitochondrion increased significantly with age (Fig. 5). Because mitochondria did not appear swollen in any age group, this finding indicates that mitochondria increase in size with age, as it is also evident by comparing Figs. 1 and 2; and (4) in each of the four age groups, the mean percentage of perikaryal volume occupied by mitochondria and the mean size of mito-

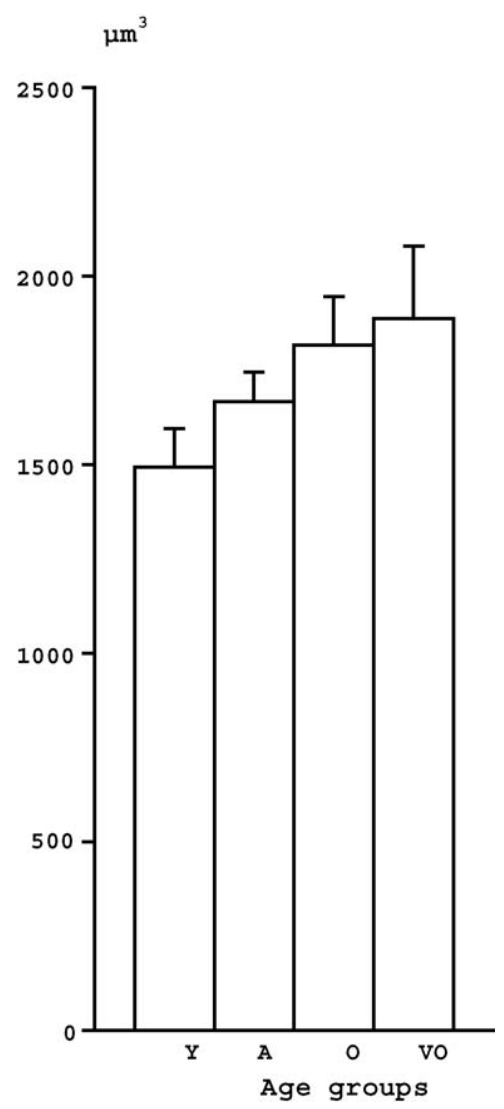

Fig. 3. Total volume of mitochondria $\left(\mu \mathrm{m}^{3}\right)$ within the perikarya of spinal ganglion neurons of rabbits aged 1 year (young, Y), 3.6 years (adult, A), 6.7 years (old, O), and 8.8 years (very old, VO). Values are means \pm S.E.: $\mathrm{Y}=1493.683 \pm 101.268, \mathrm{~A}=1667.023 \pm 78.974, \mathrm{O}=1817.620 \pm 128.570$, and $\mathrm{VO}=1886.869 \pm 192.298$. These values did not differ significantly (ANOVA).

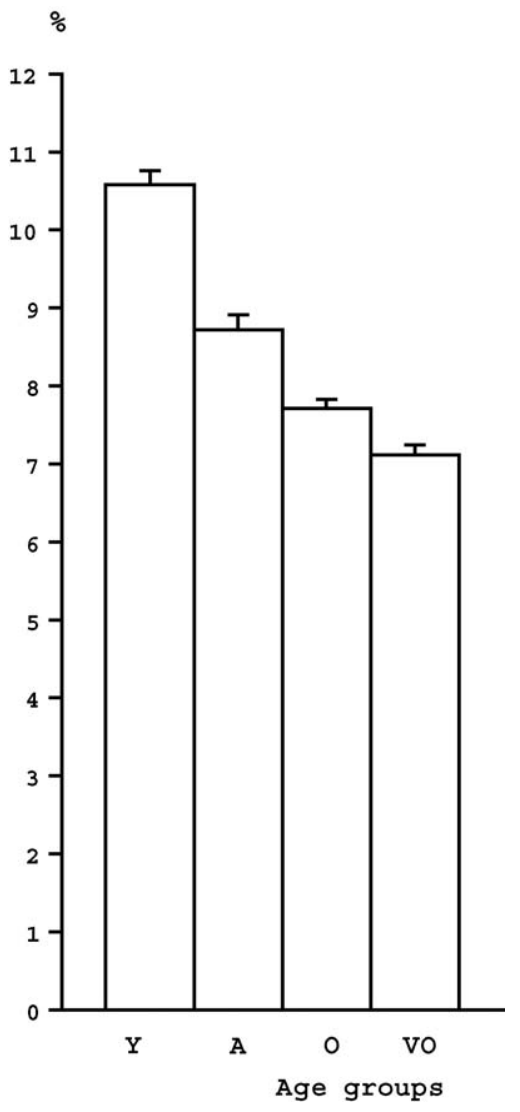

Fig. 4. Percentage of perikaryal volume occupied by mitochondria in spinal ganglion neurons of rabbits aged 1 year (young, Y), 3.6 years (adult, A), 6.7 years (old, O), and 8.8 years (very old, VO). Values are means \pm S.E.: $\mathrm{Y}=10.585 \pm 0.180, \mathrm{~A}=8.723 \pm 0.190, \mathrm{O}=7.710 \pm 0.121$ and $\mathrm{VO}=7.126 \pm 0.125$. The differences between $\mathrm{Y}$ and $\mathrm{A}, \mathrm{Y}$ and $\mathrm{O}, \mathrm{Y}$ and $\mathrm{VO}, \mathrm{A}$ and $\mathrm{O}, \mathrm{A}$ and $\mathrm{VO}$, and $\mathrm{O}$ and $\mathrm{VO}$ are significant $(P<0.05$, Tukey test).

chondria were very similar in large light and in small dark neurons.

\section{Discussion}

Some of the quantitative results we have obtained on spinal ganglion neurons in adult rabbits are consistent with findings for other regions of the nervous system. For example, we found that in adult animals the mean percentage of perikaryal volume occupied by mitochondria was very similar in large light and in small dark neurons, as also found by Gabella et al. (1988) in the sheep superior cervical ganglion. We also found that the mitochondria occupied $8.70 \%$ of the perikaryal volume, similar to percentages reported for other regions of the nervous system in adult animals (rabbit hypoglossal nucleus: Hudson et al., 1961; rat supraoptic nucleus: Eneström and Hamberger, 1968; rat olfactory bulb: Hinds and McNelly, 1979; sheep superior cervical ganglion: Gabella et al., 1988). However, larger percentages have been reported for other sites (rat auditory cortex: Peters and Vaughan, 1981; rat spinal 


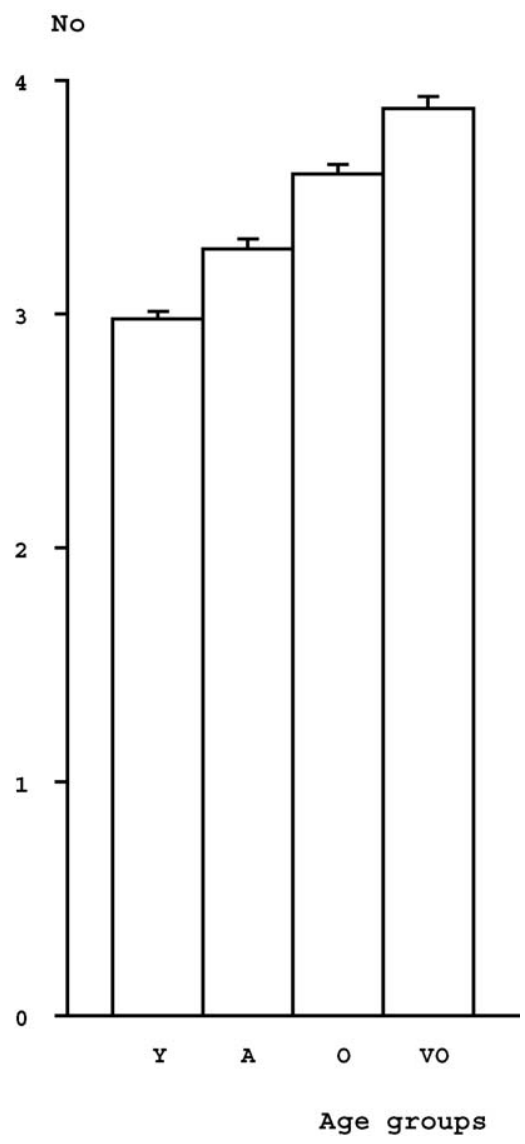

Fig. 5. Number (No) of points falling on a mitochondrion in the perikarya of spinal ganglion neurons of rabbits aged 1 year (young, Y), 3.6 years (adult, A), 6.7 years (old, O), and 8.8 years (very old, VO). Values are means \pm S.E.: $\mathrm{Y}=2.984 \pm 0.029, \mathrm{~A}=3.284 \pm 0.036, \mathrm{O}=3.592 \pm 0.043$, and $\mathrm{VO}=3.884 \pm 0.054$. The differences between $\mathrm{Y}$ and $\mathrm{A}$, and $\mathrm{O}$ and $\mathrm{VO}$ are not significant, whereas the differences between $\mathrm{Y}$ and $\mathrm{O}, \mathrm{Y}$ and $\mathrm{VO}, \mathrm{A}$ and $\mathrm{O}$, and $\mathrm{A}$ and $\mathrm{VO}$ are significant $(P<0.05$, Tukey test).

cord: Ishihara et al., 1997). The reasons for these differences are unclear. Finally, we found that the mean size of mitochondria increased significantly with age, as did Tauchi and Sato (1968), Wilson and Franks (1975), and Bertoni-Freddari et al. (1993) at other sites. However, Herbener (1976) found no changes in mitochondrial size with age in mouse heart or liver.

It is noteworthy that in rabbit spinal ganglion neurons the total volume of mitochondria did not change significantly during life. This indicates that in these neurons mitochondrial degradation was completely compensated by the production of new mitochondria even in the extremely advanced age. This result is consistent with the observations that the number of spinal ganglion neurons does not decrease (Emery and Singhal, 1973; Ohta et al., 1974; La Forte et al., 1991) or declines minimally (Bergman and Ulfhake, 1998) with increasing age. However, we also found that the perikaryal volume of rabbit spinal ganglion neurons increased during life and that the percentage of perikaryal volume occupied by mitochondria decreased significantly with age. A similar result was obtained for neurons of the rat vestibular ganglion
(Lyon and King, 1997) and for non-nervous tissues (Tauchi and Sato, 1968; Herbener, 1976). By contrast, the percentage of cytoplasmic volume occupied by mitochondria remained stable with age in pyramidal cells of the rat auditory cortex (Peters and Vaughan, 1981) and in the rat superior laryngeal nerve (Rosenberg et al., 1989), but increased from 27 to 30 months in the mitral cells of the rat olfactory bulb (Hinds and McNelly, 1979). Ledda et al. (1999) found that in rabbit spinal ganglion neurons the percentage of perikaryal volume occupied by lipofuscin was very low, although it did increase with age $(0.36 \%$ at 12 months and $2.55 \%$ at 79 months). Hence, our observed decrease with age in the percentage of perikaryal volume occupied by mitochondria is only in very small part due to lipofuscin accumulation. It is therefore clear that, in the neurons studied, the ratio of the total volume of mitochondria to the volume of functionally active cytoplasm (i.e., the total cytoplasmic volume minus lipofuscin volume) decreased with age. Therefore, as noted above, during senescence the mitochondria of rabbit spinal ganglion neurons are able to divide at a sufficient rate to completely compensate for mitochondrial degradation. However, they seem unable to adapt their total volume to the increasing volume of functionally active cytoplasm. This result is consistent with the observation that the neurons of old animals have a reduced ability to respond to high energy demands (e.g. see Sylvia and Rosenthal, 1979).

\section{References}

Bergman, E., Ulfhake, B., 1998. Loss of primary sensory neurons in the very old rat: neuron number estimates using the disector method and confocal optical sectioning. J. Comp. Neurol. 396, 211-222.

Bertoni-Freddari, C., Fattoretti, P., Casoli, T., Spagna, C., Meier-Ruge, W., Ulrich, J., 1993. Morphological plasticity of synaptic mitochondria during aging. Brain Res. 628, 193-200.

Cortopassi, G.A., Wong, A., 1999. Mitochondria in cellular aging and degeneration. In: Cadenas, E., Packer, L. (Eds.), Understanding the Process of Aging. The Roles of Mitochondria, Free Radicals, and Antioxidants. Marcel Dekker, New York, Basel, pp. 293-310.

Emery, J.L., Singhal, R., 1973. Changes associated with growth in the cells of the dorsal root ganglion in children. Dev. Med. Child Neurol. $15,460-466$.

Eneström, S., Hamberger, A., 1968. Respiration and mitochondrial content in single neurons of the supraoptic nucleus. A correlative study in osmotic stress. J. Cell Biol. 38, 483-493.

Gabella, G., Trigg, P., McPhail, H., 1988. Quantitative cytology of ganglion neurons and satellite glial cells in the superior cervical ganglion of the sheep. Relationship with ganglion neuron size. J. Neurocytol. 17, 753-769.

Harkness, J.E., Wagner, J.E., 1983. The Biology and Medicine of Rabbits and Rodents, second ed. Lea and Febiger, Philadelphia.

Herbener, G.H., 1976. A morphometric study of age-dependent changes in mitochondrial populations of mouse liver and heart. J. Gerontol. $31,8-12$.

Hinds, J.W., McNelly, N.A., 1979. Aging in the rat olfactory bulb: quantitative changes in mitral cell organelles and somato-dendritic synapses. J. Comp. Neurol. 184, 811-820.

Hudson, G., Lazarow, A., Hartmann, J.F., 1961. A quantitative electron microscopic study of mitochondria in motor neurones following axonal section. Exp. Cell Res. 24, 440-456. 
Ishihara, A., Hayashi, S., Roy, R.R., Tamada, Y., Yokoyama, C., Ohira, Y., Edgerton, V.R., Ibata, Y., 1997. Mitochondrial density of ventral horn neurons in the rat spinal cord. Acta Anat. 160, 248-253.

Kadenbach, B., Münscher, C., Frank, V., Müller-Höcker, J., Napiwotzki, J., 1995. Human aging is associated with stochastic somatic mutations of mitochondrial DNA. Mutat. Res. 338, 161-172.

La Forte, R.A., Melville, S., Chung, K., Coggeshall, R.E., 1991. Absence of neurogenesis of adult rat dorsal root ganglion cells. Somatosens. Mot. Res. 8, 3-7.

Ledda, M., Barni, L., Altieri, L., Pannese, E., 1999. Amount and distribution of lipofuscin in nerve and satellite cells from spinal ganglia of young adult and aged rabbits. J. Submicrosc. Cytol. Pathol. 31, 237-246.

Ledda, M., Martinelli, C., Pannese, E., 2001. Quantitative changes in mitochondria of spinal ganglion neurons in aged rabbits. Brain Res. Bull. 54, 455-459.

Lyon, M.J., King, J.M., 1997. Aging rat vestibular ganglion: II. Quantitative electron microscopic evaluation. Ann. Otol. Rhinol. Laryngol. 106, 753-758.

Mattfeldt, T., Mall, G., Gharehbaghi, H., Möller, P., 1990. Estimation of surface area and length with the orientator. J. Microsc. 159, 301-317.

Miquel, J., Economos, A.C., Fleming, J., Johnson Jr., J.E., 1980. Mitochondrial role in cell aging. Exp. Gerontol. 15, 575-591.

Ohta, M., Offord, K., Dyck, P.J., 1974. Morphometric evaluation of first sacral ganglia of man. J. Neurol. Sci. 22, 73-82.

Ozawa, T., 1995. Mitochondrial DNA mutations associated with aging and degenerative diseases. Exp. Gerontol. 30, 269-290.
Pannese, E., 1994. Neurocytology. Fine Structure of Neurons, Nerve Processes, and Neuroglial Cells. Georg Thieme Verlag, Stuttgart, New York.

Pannese, E., Bianchi, R., Calligaris, B., Ventura, R., Weibel, E.R., 1972. Quantitative relationships between nerve and satellite cells in spinal ganglia. An electron microscopical study. I. Mammals. Brain Res. 46, 215-234.

Peters, A., Vaughan, D.W., 1981. Central nervous system. In: Johnson Jr., J.E. (Ed.), Aging and Cell Structure, vol.1. Plenum Press, New York, London, pp. 1-34.

Rosenberg, S.I., Malmgren, L.T., Woo, P., 1989. Age-related changes in the internal branch of the rat superior laryngeal nerve. Arch. Otolaryngol. Head Neck Surg. 115, 78-86.

Sylvia, A.L., Rosenthal, M., 1979. Effects of age on brain oxidative metabolism in vivo. Brain Res. 165, 235-248.

Tauchi, H., Sato, T., 1968. Age changes in size and number of mitochondria of human hepatic cells. J. Gerontol. 23, 454-461.

Wallace, D.C., 1992. Diseases of the mitochondrial DNA. Annu. Rev. Biochem. 61, 1175-1212.

Walter, P.B., Beckman, K.B., Ames, B.N., 1999. The role of iron and mitochondria in aging. In: Cadenas, E., Packer, L. (Eds.), Understanding the Process of Aging. The Roles of Mitochondria, Free Radicals, and Antioxidants. Marcel Dekker, New York Basel, pp. 203-227.

Weisbroth, S.H., Flatt, R.E., Kraus, A.L., 1974. The Biology of the Laboratory Rabbit. Academic Press, New York, San Francisco, London.

Wilson, P.D., Franks, L.M., 1975. The effect of age on mitochondrial ultrastructure. Gerontologia 21, 81-94. 